\title{
Presentación simultánea de quiste hidatídico hepático y pélvico primario intraperitoneal
}

\author{
Simultaneous presentation of primary pelvic intraperitoneal and hepatic \\ hydatid cyst
}

Marcelo A. Beltrán S. ${ }^{1}$, Lorena A. Sánchez O. ${ }^{1}$, Andrea A. Beltrán C. ${ }^{2}$

Paciente masculino de 59 años de edad que consultó por un cuadro clínico de 4 meses de evolución con aumento progresivo del contorno abdominal y constipación. Se estudió con una tomografía computarizada (TC) abdominal y pelviana encontrándose un quiste hidatídico hepático en coexistencia con un quiste hidatídico pélvico de similar tamaño (Figuras 1 y 2). Al examen físico la región hipogástrica del abdomen se encontraba distendida (Figura 3A). El paciente fue operado mediante una laparotomía mediana supra e infraumbilical con extensión subcostal derecha. Inicialmente se resolvió el quiste pélvico resecándolo en bloque sin abrir la cápsula (Figuras 3B y $3 \mathrm{C}$ ). Posteriormente se destechó el quiste hepático que contenía líquido amarillento y múltiples membranas desvitalizadas. Después de resecar la cápsula y la mayor parte de la periquística se evidenció una comunicación con la vía biliar derecha de $1 \mathrm{~cm}$ de diámetro la cual se reparó con suturas de monofilamento absorbible (Figura 3D). Finalmente, y después de realizar una colecistectomía se exploró la vía biliar, no se encontraron membranas en su interior y una colangiografía demostró la indemnidad del tracto biliar (Figura 3E). La localización peritoneal primaria de los quistes hidatídicos es infrecuente y representa solo el $4 \%$ de todos los ca$\operatorname{sos}^{1,2}$, la localización pélvica intraperitoneal primaria se ha reportado solo en $10 \%$ de todos los pacientes con quistes peritoneales ${ }^{1,3}$, existen escasos reportes de la coexistencia de quistes hidatídicos hepáticos y pélvicos ${ }^{3}$.

\section{Responsabilidades éticas}

Protección de personas y animales. Los autores declaran que para esta investigación no se han realizado experimentos en seres humanos ni en animales.

Confidencialidad de los datos. Los autores declaran que en este artículo no aparecen datos de pacientes.

Conflictos de interés: no hay.
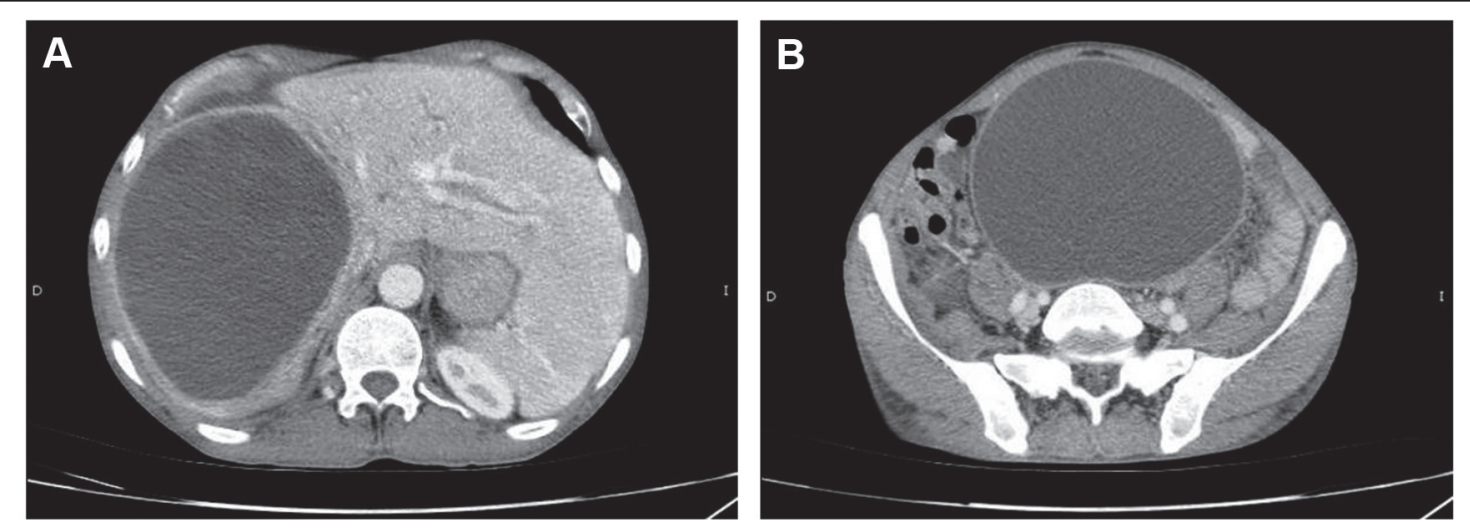

'Servicio de Cirugía, Hospita San Juan de Dios de La Serena. La Serena, Chile. 2Facultad de Medicina, Universidad de Santiago de Chile. Santiago, Chile.

Recibido 2020-07-18 y aceptado 2020-07-21

Correspondencia a: Dr. Marcelo A. Beltrán S. beltran_01@yahoo.com
Figura 1. A. Ventana transversal sobre el hígado. Se observa un quiste hidatídico que contiene membranas y que ocupa gran parte del lóbulo hepático derecho. B. En la pelvis se observa otro quiste hidatídico de similar tamaño. 

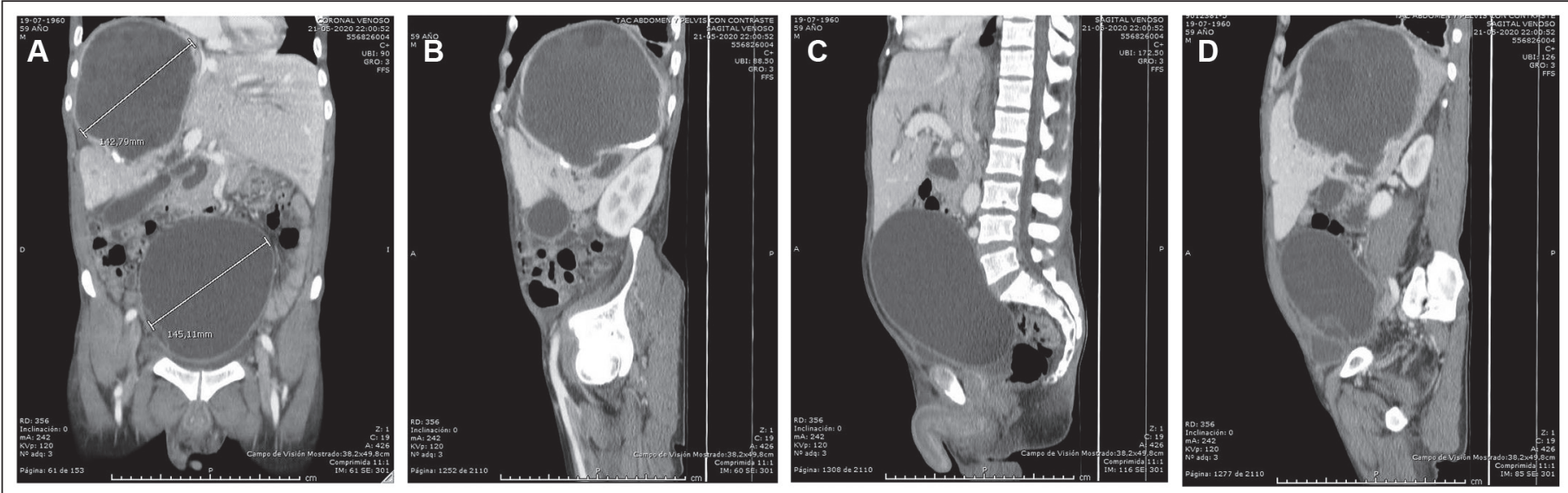

Figura 2. A. Fase venosa tardía, vista coronal. Ambos quistes tienen un diámetro mayor a $14 \mathrm{~cm}$. B. Ventana sagital que muestra el quiste hidatídico con membranas y algunas calcificaciones en la periquística. C. Ventana sagital que muestra el quiste pélvico que comprime colon sigmoides y recto superior lo cual podría explicar el cuadro de constipación del paciente. D. Plano sagital en el que se observan ambos quistes. El quiste hepático tiene membranas y vesículas hijas en su interior, en el quiste pélvico se observan también algunas membranas, pero no se observan vesículas hijas.

Figura 3. A. La región hipogástrica del abdomen del paciente se encontraba distendida y tensa por el quiste hidatídico. B. Quiste pélvico in-situ instantes previos a su resección. C. El quiste pélvico se resecó en bloque sin dañar la cápsula. D. El quiste hidatídico fue destechado y después de resecar la mayor parte de la periquística se observó una comunicación con la vía biliar derecha que medía aproximadamente $1 \mathrm{~cm}$ de diámetro. En la Figura se observa una pinza de disección dentro de la vía biliar. Este defecto se reparó con puntos separados de sutura monofilamento absorbible. E. Después de la exploración de la vía biliar se tomó una colangiografía que evidencia la indemnidad de la reparación de la comunicación biliar con el quiste hidatídico, no se observaron filtraciones u otros defectos.



\section{Bibliografía}

1. Delis SG, Bakoyiannis A, Exintabelones

T, Triantopoulou C, Papailiou J, Dervenis

C. Rare localizations of the hydatid disease. Experience from a single center. J Gastrointest Surg. 2007;11:195-8.

2. Prousalidis J, Tzardinoglou K, Sgouradis L, Katsohis C, Aletras, H. Uncommon sites of hydatid disease. World J Surg.
1998;22:17-22

3. Manuel A, Latorre R, Gijón L, Ramia JM. Hidatidosis pélvica como localización excepcional. Rev Esp Enferm Dig. 2019;111:239-40. 